\title{
Beauty, the Ethics and Technology of Identity Alteration
}

\section{Bamikole LO*}

Department of Language, Linguistics and Philosophy, The University of the West Indies, Jamaica

*Corresponding author: Lawrence 0 Bamikole, Department of Language, Linguistics and Philosophy, The University of the West Indies, Mona, Jamaica, Email: lawrence.bamikole@

\begin{tabular}{|c|}
\hline Conceptual Paper \\
Volume 4 Issue 4 \\
Received Date: October 26, 2021 \\
Published Date: November 29, 2021 \\
DOI: $10.23880 /$ phij-16000204 \\
\hline
\end{tabular}
uwimona.edu.jm

\section{Abstract}

The thrust of this paper is that there is an existential relationship between beauty and identity and that identity alteration through the beautification of the body and the mind can produce a new human either for good or for bad. The paper observes that human beauty is multidimensional. There is an outer beauty as well as an inner beauty. Outer beauty relates to human's physical appearance, while inner beauty is connected to human inner (psychological, social, ethical, spiritual) nature. If carefully and reflectively juxtaposed, outer and inner beauty can function harmoniously to produce a human being who is capable of living a good life. However, human beings are agential beings who can initiate, embark and act out actions that can enable them to alter their identities, either for good or for bad. Within the physical, bodily realm, identity can be altered through many forms of bodily beautification, such as skin bleaching, piercings, tattooing, and cosmetic surgeries, making use of technologically derived chemical agents. In many instances, such identity alteration produces a being of double consciousness in the Duboisan sense; a person of split personality who can no longer say precisely who s/he is. In some other instances, attempts to alter bodily identity through beautification by cosmetic surgery has led to premature death. On the other hand, within the realm of the inner, minded realm, identity can be altered through the moulding and beautification of one's character, resulting in the creation of a new human being who can use his/her newfound identity to change the world and humanity for the better.

Keywords: Beauty; Ethics; Aesthetics

\section{Introduction}

Aesthetics is one of the traditional core branches of philosophy. Simply defined, aesthetics means theory of beauty. This simple definition may be contested on the ground that aesthetics deals with other kinds of subjects apart from beauty. As Goldblatt and Brown [1] observed, Aesthetics is not a unified discipline; rather, it deals with different areas of the arts. The arts include, among others, music, film, painting, sculptor, performance, among others.

However, many philosophers have argued that all the arts, no matter how diverse in form and function, really do have some fundamental in common. For instance, Dewey
[2] observed that in a work of art, different acts, episodes, occurrences melt and fuse into unity, and yet do not disappear and lose their own character as they do so.

Whatever the argument for or against whether the arts are diverse or whether they form a unity, aesthetics has been traditionally related to the idea of beauty. This view has been echoed by Hanfling [3] in his view that whatever surprises the continuing history of art may have in store for us, it is likely that the traditional association of art with beauty will remain. In the same vein, Sontag [4] observes that "The subtraction of beauty as a standard for art hardly signifies a decline of the authority of beauty. Rather, it testifies to a decline in the belief that there is something called art". The 


\section{Philosophy International Journal}

inherent association of aesthetics with beauty has made some authors to define aesthetics in relation to beauty. For instance, Lawal [5] defines aesthetics as a discipline that "deals with philosophy of the beautiful as well as with the standards of value in judging art and other aspects of human life and culture. And Hanfling [3] observed, "Aesthetics is a branch of philosophy dealing with the nature of art, beauty, and taste, with the creation and appreciation of beauty. As observed earlier, these views acknowledge the fact that the notion of beauty occupies a pride of place in any definition of aesthetics.

The most important thing that could be said about works of art is whether they are beautiful or ugly. This assumes that there is a kind of standard that is used to evaluate works of arts. This standard will not pertain to a particular work of art; rather, it is a criterion of evaluation applicable to any work of art. The history of aesthetics however suggests that given the nature of human value and evaluation, there might not be objective criteria for evaluating aesthetical things. It is in this connection that this paper will undertake an analytical examination of the concept of beauty as an aesthetic category. My exploration will focus on theories of beauty across major philosophical traditions; namely, Western, Asian, African and Caribbean philosophical traditions. This will enable us to have an account of beauty which cuts across many philosophical traditions, which, in turn, will further enhance our comprehensive understanding of the concept in its various dimensions and interpretations.

\section{The Problem}

In our day to day reference to the notion of beauty, there are a number of phrases that seem to represent our general conceptions of beauty; namely, (i) "Beauty is in the eye of the beholder", (ii) "Beauty is only skin deep, (iii) "True beauty comes from within", (iv) "There is no accounting for taste". These phrases signify different ways of conceiving beauty in relation to its perception. These phrases relativize beauty by locating it within the outer and inner spheres of the individual. What is troublesome in these phrases is that all have often been taken as axiomatic truths at the level of pre-reflective thinking. However, when one undertakes a reflective examination of the concept of beauty, the conceptual and practical problems in these phrases will start to emerge.

The philosophical problem of beauty could be seen along the different branches of philosophy. In its metaphysical form, the question of beauty relates to what is beauty in itself apart from things that are beautiful. This is a reflection of Plato's essentialism. But the question that arises is how does the concept of beauty relate to its instantiations? In its epistemological dimension, the problem of beauty relates to whether beauty stands for an objective property in something that is beautiful or whether the beauty of things is related to how individual perceiver perceives beauty. Is beauty a real object or is beauty constructed? It might also be connected with the general problem of identifying who is a perceiver, what is being perceived and what is it to perceive something. The ethical aspect relates to how beauty is connected with human (moral and spiritual) character; the existential question is how beauty is related to identity and the aesthetical question is about how existence in human and non-human entities is related to beauty.

These are universal questions but which responses are determined by cultural and historical conditions and situations. To explore critically and comprehensively the meaning of beauty as it has featured in the works of scholars and thinkers along different philosophical traditions and epochs, is another way of interrogating the words "beholder" and "behold" for it shows how different thinkers and scholars within different philosophical traditions and epochs have thought about the meaning of a beholder and what is beheld in relation to beauty. On another dimension, the positions held by these philosophical traditions and epochs can also shed light on their different theories of beauty in relation to its perception by persons within these philosophical traditions and epochs. As observed by Sontag [4] the best theory of beauty is its history. For her, thinking about the history of beauty means focussing on its deployment in the hands of specific communities. This is also why a good theory of beauty is also culturally and historically determined.

\section{Beauty: A Conceptual Analysis}

What then is beauty? This question might take the form of asking about the definition of beauty. Taken from this perspective the dictionary may be of some assistance. According to the Pocket Oxford English Dictionary, beauty is a combination of qualities that delights the senses [6]. The definition makes beauty a positive concept because of its delighting nature. This definition also sees beauty as a form of relation: something is beautiful in relation to those persons who are able to perceive objects of beauty. Despite this positive concept, the definition is still loaded with meaning. It requires us to ask further questions about what quality is and its various senses and the type of being that possesses these qualities. Qualities are certain attributes possessed by natural and non- natural objects, human and non- human existences. Locke identifies two kinds of qualities-primary and secondary. Primary qualities, such as extension, shape, and weight are said to be in the objects; while secondary qualities such as colour, smell, sound texture are not in objects; rather, they are mere powers in objects 


\section{Philosophy International Journal}

to exert in us a particular experience. This distinction helps to clarify the two dimensional aspects of beauty-external beauty and internal beauty. External beauty is perceived by human's sense organs - our 5 senses of sight, sound, taste, smell, hearing, and feeling. Apart from our physical senses, we also possess intellectual, moral and spiritual senses that are related to cognitive abilities, that enable us to evaluate experiences that are related to our character and attitudes and of course, spiritual sense that is related to the experience of the supra-sensible.

Donoghue [7] holds the view that beauty is a value to be perceived in its diverse manifestations. For her, aesthetics is the theory of such perception. The manifestations of beauty are all around us; the adjective beautiful is used in many phrases, referring to both animate and inanimate things, but the noun 'beauty' itself remains enigmatic in its conception and perception. What is enigmatic about the noun beauty?

The response to this question could relate to the general decline in the use of abstractions or general terms, a philosophy that was well known with Plato and Locke. The use of abstraction and general terms however declined in the $20^{\text {th }}$ century through the school of linguistic philosophy, which saw philosophy as the analysis of language and thereby stipulating that general and abstract term are remnants of metaphysical speculation that does not have any value for experience. In addition, the problem can be conceived from Moore's theory of definition. According to Moore, beauty as a noun could be seen as indefinable because it is already a simple notion, which cannot be further divided to parts $(1904,9)$ What Moore suggested was that the only way by which such simple notions could be discerned is for individuals to put it in his or her mind's eye. In other words, Moore was suggesting that it is one's intuition that can give a true picture of what beauty is. Moore could then be identified as one of the authorities that support the phrase that "beauty is in the eye of the beholder".

That beauty is in the eye of the beholder, suggests that all things dealing with beauty are condemned to the realm of subjectivity in the epistemic sense. What follows from this position is that there is no objective beauty and any controversy relating to beauty could not be settled rationally. This problem is summarised by Schmalzried, "The big challenge of every theory of beauty is to explain the tension between subjectivity and objectivity. Either it has to explain the subjectivity in objective terms, or the objectivity in subjective terms, or it has to find a way to preserve both the subjectivity and the objectivity" [8]. It has been the task of classical, medieval, modern and contemporary Western scholarships on beauty to respond to this problem. This is a large issue that is beyond the scope of this paper.

\section{Western Conceptions of Beauty}

Within Western scholarship, the concept of beauty has undergone a chequered history. It would be generally expected that the concept of beauty will enjoy some form of approbation within the classical period in Western philosophy, especially as enunciated by Plato and Platonists. There was within this period a disposition to the use of abstractions and to identify such abstractions with intrinsic values. As intrinsic values, these concepts are believed to have values in themselves independently of their identification with objects. On this understanding, beauty has as its symmetry, goodness and truth. The preference of abstractions over natural objects reflects the rationalist flavour in the systems of thought of Plato and the Platonists. It also suggests how the school of thought rated reason over experience. According to the rationalist school, objects that are given in experience cannot be real because it is always becoming and whatever is becoming does not have reality in itself. The only real thing is what our reason depicts to us and reality of such thing lies in its stable nature. The usual critique of this kind of reasoning is the question of the relationship between the Forms and the particular things which instantiate them. For instance, what is the relationship between beauty and beautiful things?

The question of the relationship between concepts and their instantiations is the problem of universals. The history of Western philosophy is replete with the philosophical engagement about the problem of universals. That it is a philosophical problem is reflected in the inability to arrive at a definite response to this problem. Responses to the problem of universals have taken different forms, such as realism, whether of the Platonic or the Aristotelian type; nominalism, Wittgenstein's doctrine of family resemblance and other logical doctrines of the $21^{\text {st }}$ century.

The $19^{\text {th }}$ century's response to the problem of universals and hence to the concept of beauty is to discredit the use of abstractions. The use of abstractions was popular with Plato and the Platonists and Locke in the modern era of philosophy. It however declined in the $20^{\text {th }}$ century through the school of linguistic philosophy, which main concerns is with the analysis of language. Thus Sontag [4] observed that since the $19^{\text {th }}$ century, in literature as in conversation, the concept of beauty has fallen into disuse. In the 19th century, beauty of body and face was more spoken of in language as the domain of the beautiful, but according to Sontag [4], is less 'uplifting'.

The position that limits the concept of beauty to the body and face is a reflection of the logical empiricists' identification of genuine and meaningful statements with statements that have only empirical content. Therefore, value 


\section{Philosophy International Journal}

judgments as found in ethics and aesthetics were disparaged as lacking in impartiality and objectivity and as such are not significant statements. Following from this, instead of talking about beauty which will involve making a value judgement, scholars have substituted for beauty the term, 'interesting'. The question arises whether equating beauty with interesting gives us the same sense when we discuss about beauty and beautiful things. Furthermore, one can ask, does the word 'interesting' convey an empirical judgment which can be considered as meaningful on the logical empiricists' criterion of meaningfulness?

The other position that identifies beauty with other intrinsic values like goodness and truth was also a subject of criticism by moral philosophers with a relativistic frame of mind. One of these moral philosophers, Frederick Nietzsche [9], put forward a doctrine of moral inversion in which value judgements are reflections of the status ones occupies in the society.

This has been substantiated by Donoghue [7] who suggested that beautiful, the adjective of beauty, belongs to the structure of social amenities that are not expected to do much work in cognition or elucidation. He went on to suggest that the adjective beautiful is relevant to the realm of action while the substantive beauty is concerned with the man (woman) of contemplation and reflection.

The consequence of this distinction is that the concept of beauty has become elitist and therefore discriminatory. It assumed that there are certain individual and groups that are capable of thinking and reflecting on beauty and some only perceive beautiful things on the basis of their sense perception. The importance of this distinction should not escape our evaluation because not all persons are gifted with contemplative capacity. The activity of contemplation requires a conscious activity of reflecting upon our experiences in the world. This is one of the features of education in a broad understanding of the term.

It was observed by Sontag [4] that much of the discrediting of beauty needs to be understood as a result of the gender inflection. This is because it is often assumed that beauty is associated more with women than men. However, women have been using unorthodox methods to promote beauty through practices like bleaching of the skin, tattoos, insertions among others. In certain cases, these practices have led to issues relating to identity altering with its attendant social and cultural consequences. Thus Sontag observes, "If women are worshipped because they are beautiful, they are condescended to for their preoccupation with making or keeping themselves beautiful. Feminine beauty is connected to mindlessness. To be concerned with one's own beauty is to risk the charge of narcissism and frivolity" [4].

However, it might be suggested that this consequence can only come as a result of looking at beauty only from an outer perspective. The history of the discussions about the concept of beauty has not always linked the concept to an outward appearance alone. Plato, for instance, suggested that beauty can take on two interpretations: the broad interpretation that encapsulated not only external feelings but internal extended to the intellect, character, spirituality, among others and the restricted conception of beauty that equates the concept with 'fineness'. By the same token, Hegel makes a distinction between beauty of art and beauty of nature, For him, the beauty of art is better, 'higher' than the beauty of nature because it is made by human beings and is the work of the spirit. But the discerning of beauty in nature is also the result of traditions of consciousness and of culture-in Hegel's language, of spirit [4].

\section{African Aesthetics and Conception of Beauty}

Abiodun [10] observed that given the nature of human knowledge and understanding in the $21^{\text {st }}$ Century, it has become necessary to search carefully within the African cultures in which art forms originate, and to use internally derived conceptual frameworks in any critical discourse on African art. The suggestion here is that understanding African art forms hinges significantly on the African culture, which stands for the total world view of the African people.

Thus, according to Onyewuenyi [11] traditional African aesthetics is grounded on the African world view. The African world view is a close knitted one in which all the elements within the system are organically related. This is why Onyewuenyi describes African art as "functional, community-oriented, depersonalized, contextualized and embedded".

By functional and community-oriented, Onyewuenyi meant that African arts are designed to serve practical meaningful purpose and that beauty of appearance is secondary. On the other hand, to say that African art is depersonalized means that the artist's concern is not to depict his/her own individual whims and feelings; rather, s/ he performs in such a way as to fulfil the ritual and social purposes of his/her community for whom the arts are meant to regulate the spiritual, political, and social forces within the community. It is also embedded because there is no "separation among artwork, the one who creates it, and the one who appreciates and evaluates it for social relevance and functionality, and its conduciveness to ontological harmony" [12] In short, for Ikuenobe [12] "Art in African cultures is functional activity that has meaning, value, and relevance 


\section{Philosophy International Journal}

within the social context and norms of a community".

This conception of African aesthetics raises many questions about the differences between Western ontology and its African counterpart. One of the implications of these differences is that certain problems that are implicated by Western conception of art seem not to be so poignant within the African conception of art. For instance, the objectivist/ subjectivist dualism could be said not to present the kind of problem it presents in Western aesthetics for African aesthetics. This is because the notion of individualism which is prevalent in Western ontology appears not to be so in African ontology. Individualism gives rise to seeing a work of art from a personal and subjective point of view which then results in the problem of arriving at an objective view of persons' relationship with the arts and the various things which are said about them. On the other hand, as observed by Ikuenobe [12] "art is a social activity, a way of life, and a technique of living, in that art is not simply what one person creates solely to be appreciated for its beauty". Thus, from the African perspective aesthetic values and tastes are never individual, they are social and communal. Our characters as persons are judged by social and communal norms. This gives objectivity to moral judgements and actions and by implication, aesthetic values.

Lawal [5] and Abiodun [13] also observed that African aesthetics makes a connection between beauty as an aesthetical category and the divine. Lawal observes that at the religious level, the High-God, Olorun, is Beauty par excellence, because as the Creator, He is the source of all that is beautiful" (p.242); while Abiodun [12] expresses the connection in the following statement, "My inquiry focuses on the concept of ase, an enigmatic and affective phenomenon in Yoruba art and culture, the creative power in the verbal and visual arts".

\section{Oriental (Indian, Chinese) Aesthetics and Conception of Beauty}

The central notion of Indian aesthetics is the notion of rasa. Aesthetic experience as manifested in beauty is holistic. Real beauty can provide pleasure, happiness and joy simultaneously-pleasure to the sense, happiness to the mind and joy to the spirit. Indian aestheticians do not engage with dualism in aesthetics; their aesthetic category, rasa, is an inclusive one.

In the same vein, Chinese aesthetics, as observed by Inada [14] consists of 4 notions-vital breath (ch'i), inner principle or structure (li), intention or active consciousness (i) and spirit or divine essence (shen). He summarises the four principles of Chinese aesthetics as follows: "A thing of beauty is always fresh, vital principled, and divine; it is the exemplification of a work in graceful and disciplined motion, as seen, for example, in the performances of a dancer, an athlete, or a devotee of $t^{\prime}$ ai-chi".

The moral of these two kinds of aesthetics is that aesthetics and aesthetical categories are concerned with the bodily, the psychological and the spiritual. These aspects of the human person constitute a harmony and they altogether replicate all aspects of aesthetic discourse.

\section{Dimensions of Beauty}

Our discussion in this section will be guided and enriched by Frederick Schiller's ( ) [9] view that every phenomenon may be thought of in 4 different connections: Firstly, a thing may relate directly to our sensuous condition (our being and well-being) that is, its physical nature; secondly, it can relate to our reason, and furnish us with knowledge; that is its logical character; thirdly, it can relate to our will, and be regarded as an object of choice for rational being; that is, its moral character and fourthly, it can relate to the totality of our various powers, without being a specific object for any single one of them; that is its aesthetic character.

The four dimensional view of thinking about a phenomenon as outlined by Schiller could be applied to the discussion about the dimensions of beauty in the sense that human beauty has always been seen along a distinction between outer beauty and inner beauty which corresponds to the first of Schlillers distinction on one hand, and the other three on the other hand. In philosophical discourses about human beauty, the distinction between 'inner' and 'outer';' 'lower' and 'higher' beauty has always been maintained across different philosophical traditions. The background underlying the distinction is not unconnected with how different philosophical traditions conceive the human person and the role assigned to each of the features that characterise the human person. In broad terms, the human person is a combination of physical and non- physical attributes. The physical aspect is the externally visible body, made up of different parts which perform different functions. There are also physical organs in the body that are not immediately visible, but which in principle, could be made visible. On the other hand the non-physical aspects include the mental, the moral, the social and the spiritual. The Western philosophical tradition represented by Rene Descartes conceives physical and non-physical aspects of the human person in dualistic terms; whereas, its non-Western counterpart, made up of Asian and African traditions, do not perceive the physical and non-physical in dualistic terms. For non-Western philosophical traditions, all the aspects of the human person form a continuum and all of them work together for the fulfilment of human purpose in the universe. Both traditions have elevated the non-physical above the physical. In general, all philosophical traditions hold that our 


\section{Philosophy International Journal}

judgements of human beauty are always dependent upon our concept of a human being.

Beauty is reflected in all the spheres of the human person-the physical, the mental, the moral, the social and the spiritual. These are dimensions of beauty. But these dimensions are related to the human person, who is also a historical and cultural being whose life is supposed to be purposive and laden with meaning. The question about the purpose and meaning of life also has implication for our conception of beauty. Just like physical objects that are designed to perform certain functions, human body parts are also designed to perform specific function and how far these parts perform these functions would enable us to evaluate them as being beautiful or ugly as the case may be. By the same token, the beauty of the human person as a whole also depends on the purpose for the existence of person in the universe as a whole or within a culture in particular.

Among all traditions, the mental (inner) is often considered as having a higher status than the physical. Sontag [4] observed that "higher beauty of art has generally been accorded an honorary citizenship in the domain of 'inner' (as opposed to 'outer') beauty. Thus, Plato and his pupil, Aristotle averred that the human person is a rational being, in the sense that they possess reason which is the faculty of mental operations, such as reasoning, planning and deciding. For Plato, the experience of beauty itself is part of a background which elevates us. For him, the lover of beauty is first captured by the beauties of individual bodies. But then, by 'scanning beauty wide horizon' the aesthetic detaches him or herself from the 'slavish and illiberal devotion to the individual loveliness of a single boy' and turns the eyes disinterestedly to the 'open sea of beauty'. For Plato, true aesthetic appreciation has been reached until it in turn comes to be love for something which is not physical at all. Plato's theory of beauty can also be replicated in his theory of the tripartite division of the soul in which the rational is given a pride of place over the appetitive and the courageous, holding that a person who is able to possess the rational faculty is the person who can rule the state as the philosopher King. And according to Lawal [5] the most important element in the Yoruba conception of human beauty is ewa inu (inner beauty) exemplified in human character. And Ikuenobe [12] observes that "beauty as applied to humans, which involves an aesthetic judgement, is not simply judgement about physical beauty based on one's physical features, but a judgement about one's moral qualities and social abilities to behave in acceptable ways in order to meet one's socialmoral obligations".

However, in line with the non-dualistic conception of the human person within the African philosophical tradition, Ikuenobe [12] observed that, "However, you need these two dimensions to make a robust sense of personhood, a beautiful person. Similarly, you need the two dimensions of human beauty-inner and outer-for someone to be truly beautiful as a combination of goodness and beauty".

In the modern era of Western philosophy, John Stuart Mill represented the modern version of the view that the mental trumps over the physical. Given that Mill was a utilitarian who held that pleasure is the only good as an end, he nevertheless made a distinction between lower and higher pleasures. For him the outer pleasure which is measurable in quantitative terms represents the pleasure of the pig, while the inner pleasure which is measurable in qualitative terms represents the pleasure of Socrates. Socrates is the expert judge who has tasted both pleasures and he is convinced that a higher pleasure is qualitatively better than a lower pleasure. By the same token, for Kant (), one's moral character is an "inward" characteristics instantiated in intentions and actions, which should be the sole or at least the weightiest factor to be considered in evaluating others.

Although these positions have often be criticised as eliciting elitism, the plausibility or otherwise of this critique is a factual matter given the fact that this is how persons across philosophical traditions have always seen the issue. Thus according to Sontag [4] beauty applied to some things and not to others, that it was a principle of discrimination, was once its strength and appeal. According to her, beauty belonged to the family of notions that establish rank, and accorded well with social, class, hierarchy, and the right to exclude. Sontag observed, however, that this virtue seems to have been turned to beauty's liability. This is because of its assumption of standards which has now been identified with discrimination, exclusion, prejudice, blindness, bigotry, etc. She therefore suggested that rather than saying beautiful, it is better to say interesting which will be seen to be more inclusive in reference. However, it remains to be seen whether 'interesting' can logically and substantially replace 'beautiful' in aesthetic discourse.

One recent account of inner beauty is that of Schmalzried [8]. Schmalzried begins her account by focusing on the second of the four phrases mentioned earlier, that is "true beauty comes from within". According to her, this phrase is amenable to two interpretations. The first links the phrase with a virtue-centred theory of beauty, according to which the beauty of the outward appearance of a person depends on the visible expression of a virtuous character. The second interpretation makes a distinction between at least two kinds of beauty, outer and an inner beauty, and the latter stands hierarchically above the former. The first interpretation was defended by Kant in Section 17 of the Critique of Judgement, while the second was defended by Plato in the Symposium. 


\section{Philosophy International Journal}

Schmalzried observes that contrary to the analytic philosophers of the twentieth century Western philosophy, who relegated the concept of beauty to the background in aesthetical discourse, the idea of beauty and inner beauty has its place in the philosophical tradition. In addition to this the internet also shows that a lot of persons have taken interest in the research about inner beauty. She identified a common thread among all the debates as follows: "Inner beauty has to be distinguished and is independent from outer beauty. Inner beauty is not about how some looks, not about the face, the body, or the figure of a person. Inner beauty is not physical, but rather psychological beauty, so to say. Inner beauty refers to the personality, character traits, and also modes of behaviour of a person. Inner beauty is about what kind of person someone is" [8].

What this position points out is that the idea of inner beauty makes sense. However, the sense it makes has to be explained and accounted for. Schmalzried devoted her paper to account for the connection between different human character traits and inner beauty. She started with moral character traits and used Kant's moral theory as an example. It will be recalled that Kant's theory of morality is deontological in the sense that in order for an action to have a moral worth, it has to conform to the categorical imperative [15]. Acting well depends on the motivation for one's action which is related to acting from the motive of duty. She however discovered certain infelicities in Kant's account. For instance, Kant's misanthrope acts according to the moral law but does not feel any inclination to act accordingly, to the effect that one can act for the sake of duty. In terms of Kant's moral theory, she has to be praised. But Schmalzried pointed out that Kant's misanthrope does not deserve to be called inwardly beautiful. She then decided to reconstruct the Kantian account of moral goodness by turning to moral character traits exhibited by persons.

She identified moral character traits as honesty, responsibility, trustworthiness, or respect for other people [8]. However, one should take note that these moral character traits are subject to other character traits, such as sensitivity, compassion and empathy, which are strictly not moral character traits.

Apart from moral character traits, there are other moral neutral character traits which also qualify as inner beauty. She identified intelligence, humour, spirit, or eloquence. Broadly speaking, such character traits are signs of higher intellectual level of a person. They can be called intellectually desirable character traits and according to Schmalzried, they contribute to the inner beauty of a person.

A fourth kind of character traits seems to be typical for an inwardly beautiful person. She observes that if someone is self- confident, charismatic, authentic, or happy with herself, this makes her at least partly inwardly beautiful.

Her next task is to account for what connects these character traits and finds the answer in Aristotle's account of a virtuous person.

In the Nicomachean Ethics, Aristotle identified several human virtues that could be identified with inner beauty. Schmalzried classified these virtues into: moral virtues, such as temperance, generosity, or courage. For Aristotle, a moral virtue is a habit of a person which manifests itself in the action of the person. Intellectual virtues- intellectual virtues are art, knowledge, prudence, reason and wisdom. These virtues are means to the good life. The next project is to account for the connection between human virtues and inner beauty. Schmalzried found this account in the idea of friendship, which she developed to account for inner beauty.

Schmalzried formulated her account in terms of hypothesis. According to her, the friendship hypothesis entails the following: "A person is insofar inwardly beautiful as she behaves towards other persons as if they were her friends and as her personality and her character traits would make her a good friend" [8] Treating someone like a friend involves that I do not cheat on her, do not lie to her, do not hurt her, or harm her, rather I protect, support, care for, and defend her. These are examples of moral actions and as such treating persons as friends implies that one treats them morally.

Schmalzried identified certain features which characterise the friendship hypothesis in relation to inner beauty:

1. The friendship -hypothesis should demand that an inwardly beautiful person treats everyone like a friend. This will prevent an inwardly beautiful person from discriminating against persons on the basis of certain features such as race, gender, religion, class, among others.

2. An inwardly beautiful person should embark on actions that are morally praiseworthy. This means that such a person takes special interests in her friends by assisting him/her in her undertakings

3. Some morally praiseworthy actions are more important than others. Morally praiseworthy actions that are related to interpersonal relationships are more important than those that happen at the level of an institution, such as the state. Thus if one wants to choose a friend between someone who pays her tax and someone who helps us, we are more likely to choose the latter.

4. The motivation behind an action matters for inner beauty. An inwardly beautiful person effortlessly or out of love and affection acts morally, the same holds for 


\section{Philosophy International Journal}

a friend. So treating someone as a friend means that friendship is the motivating factor.

5. The four character traits earlier identified by Schmalzried which are features of inner beauty also matter for friendship.

6. Friendship depends on reciprocity. According to Aristotle, "friendship is reciprocated goodwill".

Schmalzried identified the advantage of the argument that connects the friendship hypothesis with inner beauty. According to her, inner beauty is closely connected to friendship. Friendship and love are related, and it is widely assumed that beauty in general and love are related. The first thing that exerts love in a person is his/her appearance, outer beauty. This attraction also connects with sexual attraction. However, on a closer interaction one starts to notice other features in one's partner that do not have much to do with outer beauty. These are some of the virtues we talked about earlier. It is these virtues that explain the basis of friendship, hence linking it with inner beauty. So the friendship hypothesis points to one similarity between inner beauty and beauty in general. Thus, it is often assumed that judgements about beauty are subjective. But this is not the whole story about judgements of beauty; in the history of the interrogation of beauty, there has always been the tendency to move beyond subjectivism to search for objective features of beauty. The friendship hypothesis also transcends only narrow personal relationship to a more inclusive relationship to the effect that its linkage with inner beauty takes the form of a universal string that connects humanity to one another.

One argument against the notion of inner beauty derives from the metaphysical theory of materialism. Materialism claims that it is only the physical tangible thing that exists. If one should talk about existence in other realms it could only be in form of an epi-phenomenon, a by-product of the physical. Thus, in the ordinary sense, beauty is identified with outer beauty, that is features of objects that are immediately perceptible which excite immediate sensation in a perceiver; while the so called inner beauty is a product resulting from inference and reflection on outer beauty and this inference and reflection often take time. Consequently, inner beauty makes sense only in a metaphorical sense.

This position highlights the nature of philosophical argument. There is equally a reasoned argument that could be made in support of inner beauty. The notion of inner beauty makes sense when we speak about human beauty on the assumption that there are certain human features which are not immediately visible to the senses which could be apprehended through inner feelings and reflection. We can intelligibly speak about the inner aspects of human beings, such as their moral and spiritual attributes. What is even significant is that Empirical research also supports the position that a better assessment of one's personality is the totality of one's being and a person's physical appearance and outer features could only be deduced from his/her personality. The consequence of defining a person only by means of physical attributes gives rise to crass materialism which in relation to human beauty can lead to abuse of beauty. Furthermore, it is not always congenital to limit definition of words and concepts to their intensional meaning. Definition of words and concepts can also take on extensional definition. Thus, it is not always the case that definition of terms are conceived narrowly by limiting their application to a narrow aspect of reality; rather, an extended definition helps to show the richness of a word by depicting how it applies to different things and situations.

A position that supports the conception of human persons in terms of their totality of their personality could be made by considering the views of William James (1950). James speaks of the multiple selves, which include the material self, the social self, and the spiritual self, and a metaphysical pure ego. The material self is made up of body, clothes, family and home. The social self is the domain of the acknowledgement or recognition of our actions and activities by others. Finally, the spiritual self should be viewed in terms of psychic disposition or faculties. This domain includes the rational, the moral and the spiritual aspects of human being.

In line with earlier observations, James holds the view that there is a hierarchy of selves: the merely bodily at the lowest level, the spiritual at the highest, with the extracorporeal material and social selves in the middle. According to James, we learn to subordinate our lower to our higher selves. This happens through moral education as well as direct ethical judgement (intuition). For James, our encounter with other human beings allows us to judge ourselves and to develop a higher moral self. For James, each dimension of the self (material, social and spiritual) there is a degree of potentiality for growth, for a widening of the self, that requires us to forgo immediate rewards. Aboulafia quotes James as follows: of all these wider, more potential selves, the potential social self is the most interesting...by reason of its connection with our moral and religious life" [16].

The argument that favours the distinction between outer and inner beauty is strengthened by the fact that most philosophical traditions conceive of beauty along outer and inner dimensions. Within the African (Yoruba) philosophical tradition, beauty is translated as ewà. There is ewà òde (outer beauty) and êwà inú (inner beauty). Ewà òde relates to the outward appearance, while ewà inú refers to the intrinsic worth of things [5] Just as the Western philosophical tradition, ewà inú is preferable to ewà òde. 
According to Lawal [5] the most important element in the Yoruba conception of human beauty is ewà inú or character( 'iwà ) According to the Yoruba, l̀wà is the very stuff which makes life a joy because not only does it pleases Qlórun (the High God), it also endears one to the hearts of all human beings. For him, while the appreciation of ewà òde is relative and varies from person to person, the possession of ìwà is universally accepted as the sine qua non of beauty. This is the objective dimension of beauty alluded to earlier, especially as it relates to the friendship hypothesis.

Just as some thinkers within the Western philosophical tradition links inner beauty with moral, and other non-moral qualities like intelligence, courage and the spiritual, the Yoruba links ewà with ìwà (character) and intellectual qualitities like ogboń (wisdom) Other examples of inner beauty, according to Lawal are ìlera, (good health) and agbára (strength). At the religious level, Olórun is the quintessence of beauty, given His positive attributes. The orisas are also embodiment of inner beauty because of the special relationship they share with human beings who are their devotees. All the òrissà expect their devotees to imbibe good character, such as forthrightness, truthfulness, kindness, and tolerance. Ray observes this in connection with Shango," the figure's serene facial expression depicts the Shango worshipper's inner calm and self-composure. This inner state reveals one of the most important moral qualities cherished by the Yoruba, that of good character (iwa rere). It is good character, the Yoruba say, that makes someone beautiful (lewà) and enables a person to lead a moral and virtuous life" [16].

Ikuenobe [12] observes that one important character trait that the Yoruba consider to be inner beauty is patience. There is a saying in Yoruba culture that sùúrù baba ìwà (patience is the father of character). Patience, according to Ikuenobe, involves the ability to be calm under stress or pressure. Such a person can be described as a cool person. Thus there is a linkage between the moral trait, cool and the aesthetics word, "cool", thereby establishing a connection between moral goodness and beauty (ethics and aesthetics)

The Indian Philosophical tradition sees beauty as forming a continuum- physical beauty at one end and beatitude at the other end. Physical beauty leads to spiritual beauty and then to beatitude because this is chaste (Vijay Kumar Roy) [17] Using Keats as representative of Indian philosophy, Roy claims that Keats interwove body, mind and soul. He observes that without body there is no existence of mind, and without both, there is no scope of soul, imagined or understood. According to Roy, at first sight and his early poems Keats enjoys the sensuous beauty but later he realizes the real beauty, the truth of beauty that gives inner delight and is auspicious.

\section{The Concept of Identity}

Identity is either primordial or constructed. Primordial identity is related to a natural/biological identification which has an objective reference- culture, race, religion, sexuality. Here one does not have a choice in the aspects that illuminate primordial identity. On the other hand, the constructivist conception does not recognise any objective entity which exemplifies identity. A constructed view of identity is a heuristic conception which enables us to speak in a particular way.

Two questions are often asked about the notion of identity: 'Who am I' and 'What am I'

Typical responses to these questions take the form of signifying the subjective and objective dimensions of identity. The subjective dimension of identity reflects person's level of self-consciousness over a period of time. Schechtman [18] observed that the question, 'Who am I' may be asked by either of two human characters who have found themselves in a certain mental state. The first is an amnesia victim and the second, a confused adolescent. The amnesia person would seem to be asking which history his/her life is a continuation of, while the confused adolescent presumably knows his/her history but s/he is asking which of the beliefs, values and desires that $\mathrm{s} /$ he seems to have are virtually his/ her own, expressive of who s/he is. Schechtman referred to these two questions as the question of re-identification and the question of self-knowledge respectively.

When this notion of identity is contexualised, a person or group of persons that have been enslaved, colonized and racialized seem to see themselves in a particular way in accordance to the lenses of their slave and colonized masters, who because they belong to a 'favoured race' their subordinates would have to adhere to whatever values are foisted upon them. Given the long period of slavery and colonialism, especially within the Caribbean space, the enslaved and colonized have imbibed and internalized these values such that their self- knowledge is about the totality of experience that is derived from the race/culture of the slave-masters and colonized. In an interview with Carolyn Cooper [19] she emphasized this notion of identity when she observed:

"Well, I believe if as a child people tell you that you are ugly, after a time, you will have a very ugly spirit. So the pressures that are put on people in terms of what they are, in terms of the definition of what they are. You have some people that have been told all their life that they are beautiful and sometimes they become very arrogant. So there is a correlation between how people see you and how you see yourself and how that self- image affects your way of moving 
through the world. Your perception of yourself is shaped by people outside you".

However, after emancipation and independence, persons now see themselves in a different light but the memory of who they were before emancipation and colonialism still looms large in their memory and their subconscious mind. This situation is accounted for by the Du Boisian notion of double consciousness.

\section{Beauty and Identity}

When this notion of identity is juxtaposed with the concept of beauty, one is able to see how the two interplays with one another. The literature on beauty has a place for the role which race plays in our conception of beauty. Given the fact that the predominant view of beauty places more emphasis on outer beauty than inner beauty, beauty has been conceived in racial terms in relation to one's skin colour, hair colour, the shape of different aspects of the body and in some instances how one sounds to other people. For instance, within the Caribbean region, the twin phenomenon of slavery and colonialism have accounted for the racial conception of beauty. The racial conception of beauty has been conceived in ontological and existential terms. Clinton [20] catalogued the ontological and existential grounds on which Western (slave masters and colonizers) conception of beauty and its Afro-Caribbean counterpart have been compartmentalized. Quoting copiously from Eze's [21] Anthological text, the idea that whiteness signifies purity and beauty while blackness exemplifies ugliness and impurity has given rise to the standard on which beauty is assessed. In this regard, attention is focused on the physical appearance. Thus a white skin, long hair, pointed nose slim body are considered to be beautiful because these are external features of the white race. On the other hand, dark skin, short hair, plump body are considered as ugly because these are external features of the black race. The point of concern here is that the slave and colonial agencies have impressed this on the psyche of the enslaved and colonized to the extent that this false dichotomy has been internalized. The attitudes and actions of the black race have reflected this internalization, as it is witnessed by different attempts to alter the different aspects of the black body to reflect its white counterpart.

The emphasis placed on physical appearance as a standard of beauty, has in recent years, given rise to a variety of beauty practices, such as, skin bleaching, piercings, tattooing and cosmetic surgeries. These beauty practices not only alter one's aesthetic features, but also one's identity as well.

The preponderance belief of tying beauty to physical appearance has been responsible for the view that beauty is determined by how we look. However, a deeper understanding of beauty will show that beauty is not only referred to how we look, but it can also refer to human's inner features as well. As we suggested earlier on in this paper, beauty also has an inner dimension reflected in human character exemplified in virtues, such as kindness, patience, honesty, sympathy, togetherness and communal life.

Philosophers and scholars across different philosophical traditions have explored the relationship between outer and inner beauty, and how the connection is linked with identity alteration, whether in a negative sense or in a positive sense. The issue here is whether there is a correlation between how one appears from the outside and the inner feature defined by his/her character.

It is noteworthy to observe that our conceptions of identity and beauty relate to how we see ourselves and how others see us. Depending on persons' historical and cultural situations, such understanding might lead to identity alteration in different ways. If, for instance, we see ourselves as not beautiful from a particular perspective, there is a tendency for us to attempt to alter our identities to fit into the standard view so that we can see ourselves as beautiful. As we pointed out, this can be done in either a positive way or in a negative way. Our suggestion here is that it is a negative aspect of identity alteration for a black person to attempt to bleach his/her skin in order to look like white; on the other hand, if a person undergoes a character alteration in order to conform to the ideals of morality s/he can be said to be undergoing a positive identity alteration. It is my belief that identity alteration that gives rise to positive image of person is qualitatively better than identity alteration that beautifies the body but turns the owner of the body to witness double consciousness in the Duboisian sense.

\section{Dimensions of Negative/ Positive Identity Alterations}

Sontag observed that much of the discrediting of beauty needs to be understood as a result of the gender inflection. According to her, when women use different unorthodox methods to beautify their body, beauty and identity become the victim. Thus, if women are worshipped because they are beautiful, they are condescended to for their preoccupation with making or keeping themselves beautiful. The act of beautification of the body, especially by women, promotes such negative situations as loss of labour hours, dressing for the gallery and the commodification of the body in terms of selling it for commercial purposes. As Sontag [4] observed, "to be concerned with one's beauty is to risk the charge of narcissism and frivolity".

The practice and act of skin bleaching is prevalent in 


\section{Philosophy International Journal}

many Caribbean countries. The background to skin bleaching can be situated in what is considered as the standard of outer beauty by Western hegemonic standard. This sees a beautiful body as white skin, slim body, pointed nose, long hair. This standard has influenced the Caribbean notion of beauty and in order to attain this standard, various beautification practices are employed. One of them is skin bleaching. Apart from the health risks involved in skin bleaching, the practice has negative implication for the notion of identity. The skin bleacher can neither attain the natural white skin nor retain his/her natural black skin; s/he finds herself/himself experiencing double identity-neither white nor black. This is what Du Bois referred to as double consciousness. Double consciousness does not reflect stable character.

The practice of tattooing the body has also been placed under the social microscope by the Education Ministry in Jamaica. It was reported that the former Minister of Education, Youth and Information in Jamaica, Raul Reid, has warned against recruitment of male teachers who have tattoos marked in visible parts of their body. This is to discourage young students from copying them to prevent such practices among youngsters in secondary institutions, whose minds are still malleable to any kind of influence by adults.

Along the same line is the practice of contemporary act of hairdressing which is modelled along Western conception of beauty. This involves the heating up of the hair in order to stretch it to make it long as the white hair. This practice is a violation of the inner head which is regarded within the African belief system as the bearer of destiny. This does not suggest, however, that women should not beautify their heads. In traditional Yoruba society, women plait the hair, and this has a positive effect on the inner head (ori inú). According to Abiodun [13] "Although hairdressing is aesthetic and concerned with the beautification of the orîòde, it extends to the spiritual realm, influencing positively the performance of orî-inú".

On the contrary, arguments can be adduced to show that there can be positive identity alteration through inner beauty. The Yoruba hold the belief that whatever the kind of destiny one has chosen from the vineyard of Ajala, the moulder of heads, is capable of being altered by one character (ìwà).

By the same token, Kupperman [22] observed that the ethical point of the Indian and Chinese philosophical tradition, puts much emphasis on how one can modify and develop one's self and create a path of life that reflects this development. According to him, most of Bhagaard Gita is about how one can transform oneself into a person that can have a life of superlative value, and something similar is true of the early Buddhist's literature. Within Chinese ethics, most of the Analects purports to report conversation between Confucius and his students regarding the project of improving the nature of one's self. Confucius was preoccupied with how a sort-of- good person could be transformed into a deeply good person.

Positive identity alteration can also take the form of spiritual renewal through inner beauty. For instance, the Christian rituals of baptism and confirmation are ways of transforming an old (sinful self) to a new (righteous) self. $2^{\text {nd }}$ Corinthians 5: 17- says that "Therefore, if anyone is in Christ, $\mathrm{s} /$ he is a new creation; old things have passed away; behold all things have become new" $[23,24]$.

\section{Conclusion}

This paper has examined the concept of beauty as an integral part of aesthetical discourse and its relationship with identity and identity alteration. It was suggested that beauty has both outer and internal dimensions and both work hand in hand in order to describe someone as beautiful. However, the idea of beauty has taken a racial dimension in which the standard of beauty is dictated by Western (slavery, colonial) standard and this has exerted a great influence on how persons of colour have continued to see themselves as beautiful. This internalized attitude is responsible for how some persons have attempted to alter their outward appearance in order to conform to the received belief of the standard of beauty. Eventually, this bodily alteration borders on the alteration of identity with its attendant negative consequences. On the other hand, human attempts to alter their identity through inner moulding of character and attitude can produce better persons who are capable of effecting positive changes in themselves, on others, and on humanity as a whole.

\section{References}

1. Goldblatt D, Brown LB (2005) Aesthetics: A Reader in Philosophy of Arts. Upper Saddle River.

2. Dewey J (2005) Art as an Experience. In: David Goldblatt, Lee Brown B (Eds.), Aesthetics: A Reader in Philosophy of Arts, Basil Blackwell, pp: 1-23.

3. Hanfling 0 (1992) Philosophical Aesthetics: An Introduction. Blackwell.

4. Sontag S (2002) An Argument about beauty. Daedalus 131(4): 21-26.

5. Lawal B (1974) Some Aspects of Yoruba Aesthetics. British Journal of Aesthetics 14(3): 239-249.

6. Waite M (2013) Pocket Oxford English Dictionary. Oxford 
University Press.

7. Donoghue D (2002) Speaking of beauty. Daedalus 131(4): 11-20.

8. Schmalzried LK (2013) Inner Beauty- The Friendship Hypothesis. Proceedings of the European Society for Aesthetics 5: 613-635.

9. Nietzsche F (2007) Beyond Good and Evil. Helen Zimmern (Trans.), Barnes \& Noble.

10. Abiodun R (2001) African Aesthetics. The Journal of Aesthetic Education 35(4): 15-23.

11. Onyewuenyi IC (1984) Traditional African Aesthetics: A Philosophical Perspective. International Philosophical Quarterly 24(3): 237-244.

12. Ikuenobe P (2016) Good and Beautiful: A Moral-Aesthetic View of Personhood in African Communal Traditions. Essays in Philosophy 17(1): 125-163.

13. Abiodun R (1994) Understanding Yoruba Art and Aesthetics: The Concept of Ase. African Arts 27(3): 6878; 102-103.

14. Inanda KK (1997) A Theory of Oriental Aesthetics: A Prolegomenon. Philosophy East \&West 47(2): 117-131.

15. Kant I (1987) Critique of Judgement. Werner Pluhar S (Trans.), Hackett Publishing Company.
16. Aboulafia M (2008) W.E.B. DU Bois: Double Consciousness, Jamesian Sympathy, and the Critical Turn. In: Cheryl Misak (Ed.), The Oxford Handbook of American Philosophy, Oxford University Press.

17. Roy VK (2013) Satyam Shivam Sundaram: Mysticism of Beauty and the Mind of John Keats. Anglisticum Journal 2(5): 214-219.

18. Schechtman M (1990) Personhood and Personal Identity. The Journal of Philosophy 87(2): 71-92.

19. Cooper C (2010) Caribbean Fashion Week: Remodelling Beauty in "Out of Many One" Jamaica. Fashion Theory 14(3): 387-404.

20. Hutton C (2016) 'I Prefer the Fake Look': Aesthetically Silencing and Obscuring the Presence of the Black Body. IDEAZ 14: 20-32.

21. Eze EC (1997) Race and the Enlightenment. Blackwell Publishing.

22. Kupperman JJ (2010) Why Ethical Philosophy Needs to Be Comparative. Philosophy 85(332): 185-200.

23. Fanon F (2001) The Wretched of the Earth, Constance Farrington (Trans.) Penguin Books.

24. Wilkins B (1976) Friedrich Schiller's Politics of Beauty. An African Journal of Philosophy 5(1): 50-66. 